\title{
Malignancies after mitoxantrone for multiple sclerosis
}

\author{
A retrospective cohort study
}

OPEN

Mathias Buttmann, MD

Linda Seuffert, MD

Uwe Mäder, PhD

Klaus V. Toyka, MD

Correspondence to

Dr. Buttmann:

m.buttmann@uni-wuerzburg.de

\section{ABSTRACT}

Objective: To assess the therapy-related risk of malignancies in mitoxantrone-treated patients with multiple sclerosis.

Methods: This retrospective observational cohort study included all mitoxantrone-treated patients with multiple sclerosis seen at our department between 1994 and 2007. We collected follow-up information on medically confirmed malignancies, life status, and cause of death, as of 2010. Malignancy rates were compared to the German national cancer registry matched for sex, age, and year of occurrence.

Results: Follow-up was completed in 676 of 677 identified patients. Median follow-up time was 8.7 years (interquartile range 6.8-11.2), corresponding to 6,220 person-years. Median cumulative mitoxantrone dose was $79.0 \mathrm{mg} / \mathrm{m}^{2}$ (interquartile range 50.8-102.4). Thirty-seven patients $(5.5 \%)$ were diagnosed with a malignancy after mitoxantrone initiation, revealing a standardized incidence ratio of 1.50 (95\% confidence interval [Cl] 1.05-2.08). Entities included breast cancer $(n=9)$, colorectal cancer $(n=7)$, acute myeloid leukemia $(n=4,0.6 \%)$, and others (each entity $\mathrm{n}=1$ or 2). The standardized incidence ratio of colorectal cancer was 2.98 (95\% Cl 1.20-6.14) and of acute myeloid leukemia 10.44 (95\% Cl 3.39-24.36). It was not increased for other entities including breast cancer. Multivariate Cox regression identified higher age at treatment initiation but neither cumulative mitoxantrone dose (>75 vs $\left.\leq 75 \mathrm{mg} / \mathrm{m}^{2}\right)$ nor treatment with other immunosuppressive drugs or sex as a risk factor. Fifty-five patients had died, among them 12 of a malignancy and 43 reportedly of other causes.

Conclusions: While the overall incidence of malignancies was only mildly increased, the risk of leukemia and colorectal cancer was heightened. If confirmed, posttherapy colonoscopy could become advisable. Neurology ${ }^{\circledast}$ 2016;86:2203-2207

\section{GLOSSARY}

$\mathbf{A M L}=$ acute myeloid leukemia; $\mathbf{C I}=$ confidence interval; $\mathbf{M S}=$ multiple sclerosis; $\mathbf{S I R}=$ standardized incidence ratio

The cytotoxic anthracenedione mitoxantrone has shown efficacy as a disease-modifying therapy in patients with worsening relapsing-remitting, progressive relapsing, and secondary progressive multiple sclerosis (MS). ${ }^{1}$ It is the only approved disease-modifying agent for patients with secondary progressive MS without superimposed relapses. ${ }^{2}$ Generic mitoxantrone is still being used for highly active relapsing MS in countries facing economic limits for the newer immunomodulatory drugs. ${ }^{3}$ Its application is limited mainly by the occurrence of systolic cardiac dysfunction in about $12 \%$ and of acute myeloid leukemia (AML) in approximately $0.8 \%$ of treated patients. ${ }^{4}$ The mitoxantrone-associated incidence of AML has been investigated in several cohorts, ${ }^{4-6}$ but the incidence of other types of malignancies was analyzed in only a few studies, in which no increased risk was observed..$^{7-9}$

We retrospectively evaluated the occurrence of all types of malignancies in a large cohort of mitoxantrone-treated patients with MS seen at our department between 1994 and 2007 and

From the Department of Neurology (M.B., L.S., K.V.T.) and the Comprehensive Cancer Center Mainfranken (U.M.), University of Würzburg, Germany.

Go to Neurology.org for full disclosures. Funding information and disclosures deemed relevant by the authors, if any, are provided at the end of the article. The Article Processing Charge was paid by the authors.

This is an open access article distributed under the terms of the Creative Commons Attribution-NonCommercial-NoDerivatives License 4.0 (CC BYNC-ND), which permits downloading and sharing the work provided it is properly cited. The work cannot be changed in any way or used commercially. 
calculated standardized incidence ratios (SIRs) based on a comparison to the German general population.

METHODS Study design. Using an electronic search of our medical reports for "multiple sclerosis" AND "mitoxantrone" followed by manual chart review, we identified all patients with MS seen at our large German hospital-based MS center between January 1994 and December 2007 who had received mitoxantrone according to our medical records. Patient charts, questionnaires sent to patients and treating physicians, letters to registration offices, and phone calls to patients, relatives, and physicians were used to locate patients and to define patient demographics, immunosuppressive treatment history (azathioprine, cyclophosphamide, cyclosporine, methotrexate or treosulfan; not interferon $\beta$, glatiramer acetate, or glucocorticosteroids) before or after mitoxantrone, diagnoses of medically confirmed malignancies, life status, and cause of death. As prospectively defined, follow-up was considered complete in all patients for whom information on medically confirmed malignancies, present life status, and cause of death was available as of January 2011, allowing a minimum followup of 3 years after therapy initiation. Figure 1 shows our algorithm for patient ascertainment and characterization.

Standard protocol approvals, registrations, and patient consents. The Ethics Committee of the Faculty of Medicine at the University of Würzburg approved the study. All patients who could be personally contacted gave written informed consent. Because of the nature of the study and based on German law, the Ethics Committee waived the requirement for informed consent and allowed collection and analysis of information from registration offices, physicians, and relatives on all patients who could not be contacted, e.g., because they were deceased. All persons disclosing information including relatives and doctors were informed about the purpose of this study and the Ethics Committee approval, and gave consent. Collected information was anonymized by code numbers and solely used for this study.

Statistical analyses. The SIR was used to describe the incidence of malignancies in our cohort as compared to the German general population (data from Robert Koch Institute, Berlin, Germany). The SIR was defined as the ratio of observed to expected cases, taking into account age, sex, and year of occurrence in the mitoxantrone-treated patients with MS. Multivariate Cox regression was used to analyze malignancy risk factors using $\mathrm{R}$ software (version 2.15.2, package "survival"). A $p$ value $<0.05$ was considered statistically significant.

RESULTS We identified 677 mitoxantrone-treated patients with MS, of whom 676 received a complete follow-up as defined above. Among them, 17 had started mitoxantrone treatment before 1994. The table describes patient demographics, immunosuppressive treatment history, and follow-up. In most patients, mitoxantrone was administered at $12 \mathrm{mg} / \mathrm{m}^{2}$ every 3 months while a minority $(\mathrm{n}=152)$ received induction therapy with 3 monthly cycles of $12 \mathrm{mg} / \mathrm{m}^{2}$ followed by maintenance infusions every 3 months. Mitoxantrone standard doses were adjusted according to the leukocyte nadir 10 to 14 days after infusion (target range: $2-3 \times 10^{9} / \mathrm{L}$ ). Upon clinical stabilization, mitoxantrone was reduced to $5 \mathrm{mg} / \mathrm{m}^{2}$ per infusion as maintenance dose.

Malignancies. We identified 37 patients (5.5\%) in whom a malignancy was confirmed after mitoxantrone initiation according to medical reports. Entities included breast cancer $(\mathrm{n}=9$, all female), colorectal cancer $(\mathrm{n}=7)$, AML $(\mathrm{n}=4,0.6 \%)$, glioblastoma multiforme, lung, pancreatic, or prostate cancer (each $\mathrm{n}=2$ ), and 9 other types of malignancies (each $\mathrm{n}=1$ ).

Acute myeloid leukemia. Three patients with AML were diagnosed with the French-American-British M3 and one with the M4Eo subtype, all previously unreported. Median time from mitoxantrone initiation to AML diagnosis was 35 months (24,

Figure 1 Flowchart of patient ascertainment and information collection

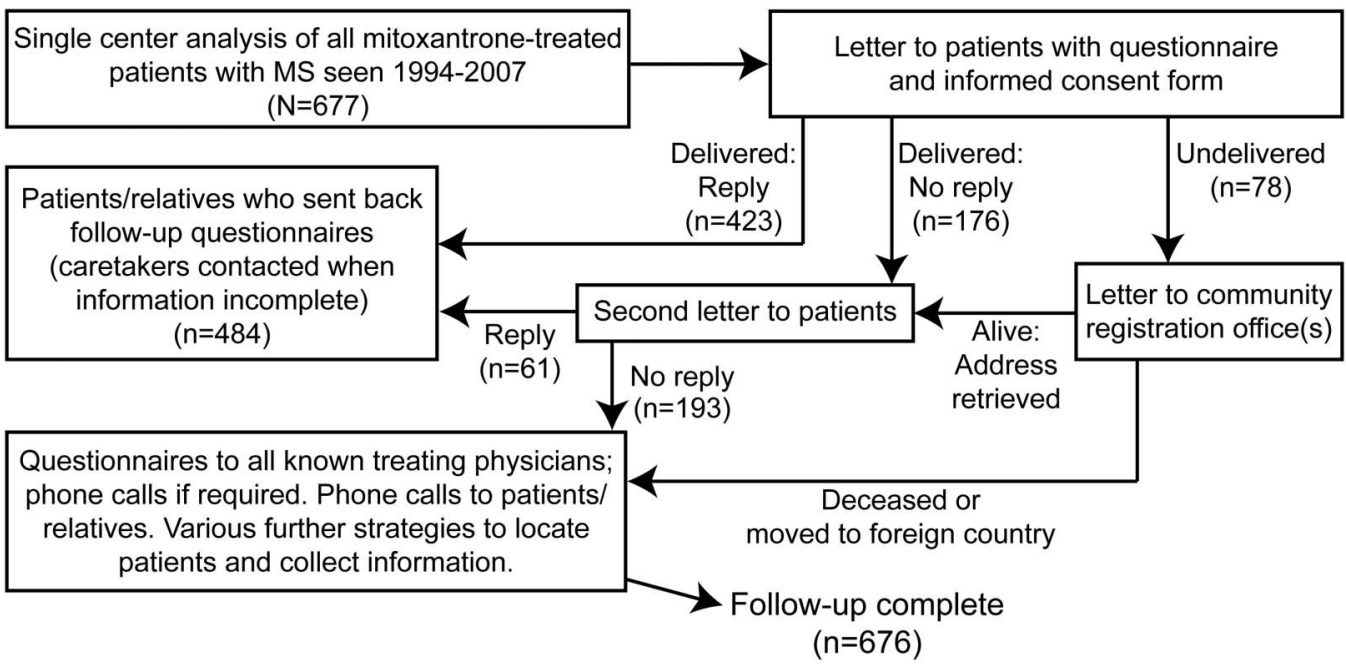

Algorithm for patient ascertainment and characterization. MS = multiple sclerosis. 
Table Patient demographics, treatment history, and follow-up $(n=677)$

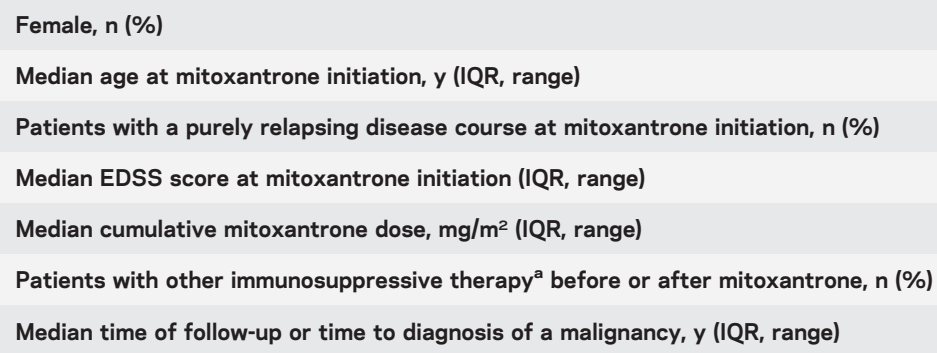

Abbreviations: EDSS = Expanded Disability Status Scale; IQR = interquartile range.

a See the Methods section for definition.

$30,40,265)$ at a median age of 38 years $(22,28,47$, $60)$. The patient with a latency of more than 20 years had also received azathioprine for 1 year, 2 years before starting mitoxantrone, while the other patients had not received other immunosuppressive drugs. Median cumulative mitoxantrone dose was $98 \mathrm{mg} / \mathrm{m}^{2}(108,87,112,51)$. All 4 patients with AML experienced full remission upon treatment and were alive at the end of follow-up.

Colorectal cancer. The 7 patients with colorectal cancer had a median age at cancer diagnosis of 58 years (range 53-73). Median cumulative mitoxantrone dose was $61 \mathrm{mg} / \mathrm{m}^{2}$ (range 36-115). The median interval between mitoxantrone initiation and cancer diagnosis was 74 months (range 12-135). At diagnosis, the tumor stage was pT3 in 6 cases and pT4 in one case; 6 had local lymph node and 4 distant metastases. Three of these patients died at age 53, 61, and 67, all from their cancer. One of 7 patients had received immunosuppressive drugs other than mitoxantrone (azathioprine for 11 years, and methotrexate or cyclophosphamide for shorter periods).

Mortality. In the whole cohort, 55 patients (8.1\%) had died, 12 of a malignancy and 43, as reported by treating physicians, of other causes. Among these, 17 patients had died of a bacterial infection, 11 of respiratory failure ascribed to MS, 4 of suicide, 3 of acute heart failure, 2 of status epilepticus, 1 of ileus, 1 of cachexia, and the remaining 4 patients of other reported reasons. No patient had a postmortem examination.

SIRs and malignancy risk factors. The SIR for any type of malignancy was mildly increased compared to the German general population. The SIRs for AML and for colorectal cancer were increased but not for any other entity including breast cancer (figure 2A). Finally, we performed multivariate Cox regression analyses to identify potential malignancy risk factors. Higher age at mitoxantrone initiation was identified as a risk factor while neither cumulative mitoxantrone dose $\left(>75\right.$ vs $\left.\leq 75 \mathrm{mg} / \mathrm{m}^{2}\right)$ nor treatment with other immunosuppressive drugs nor sex showed an influence (figure 2B).

DISCUSSION In our cohort of mitoxantrone-treated patients with MS, we observed a previously undescribed 3-fold increased incidence of colorectal cancer and a 10-fold increased incidence of AML, while the overall rate of all malignancies was only mildly increased as compared to the general population. Unfortunately, all 7 patients with colorectal cancer were diagnosed at an advanced stage-with a type of cancer that usually takes long to develop and can be treated more effectively when diagnosed earlier. ${ }^{10}$ Our incidence of AML was within the reported range. ${ }^{4-6}$ All 4 patients with AML were successfully treated, while 3 of 7 patients with colorectal cancer had died of their tumor, making colorectal cancer appear to be a more lifethreatening adverse effect than AML in our cohort.

Our study is limited by its relatively small cohort size. The risk of an underreporting bias appears low as the diagnosis of a malignancy usually represents a life-changing event for the patient that is made known to all treating physicians and the family. Bias was further reduced by collecting redundant information from various sources. The high rate of a complete follow-up in a prespecified cohort helped in overcoming some inherent weaknesses of the retrospective design. We cannot exclude that additional malignancies may have escaped proper diagnosis, because a thorough checkup was not routinely done and none of the deceased patients had an autopsy. Moreover, additional mitoxantrone-related malignancies might have developed if longer follow-up periods had been available. Both factors could result in underestimating the mitoxantrone-related risk of malignancies. Because of inconsistent data on the incidence of malignancies in patients with MS as compared to the general population, it remains unclear whether and how the chosen control group influenced our results. ${ }^{11}$ No data on the incidence of malignancies in a sizable control cohort of 
Figure 2 Incidence of malignancies and risk factor analysis



B

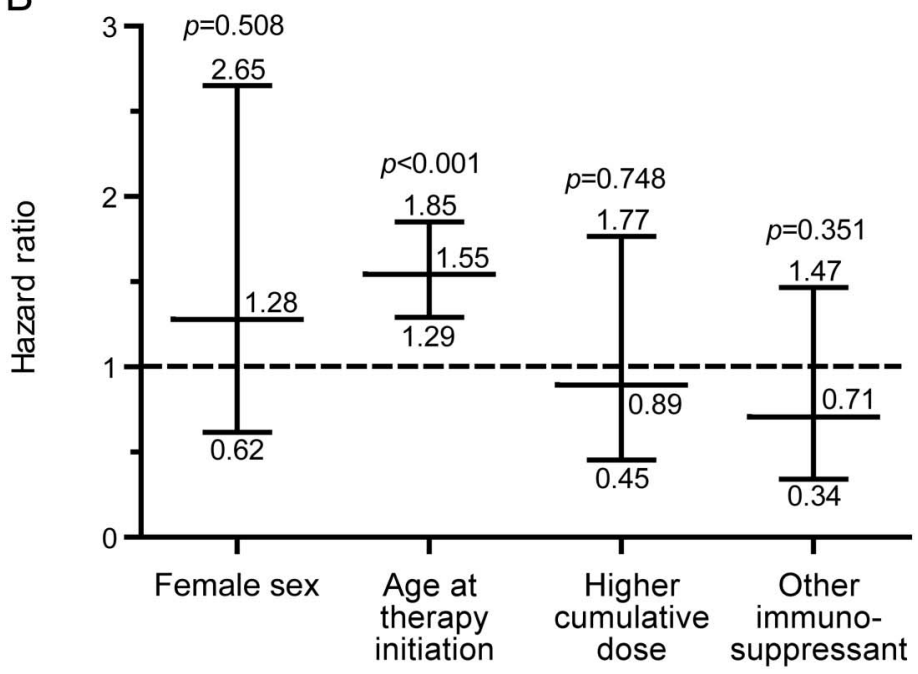

(A) Standardized incidence ratios with exact $95 \%$ confidence intervals of any malignancy or single entities in mitoxantrone-treated patients with multiple sclerosis ( $\mathrm{n}=677$; breast cancer [only females], $\mathrm{n}=455$ ) compared to the German general population (dashed line; data from Robert Koch Institute, Berlin, Germany), matched for age, sex, and year of occurrence. Note that increased frequencies are present for acute myeloid leukemia and for colorectal cancer. (B) Multivariate Cox regression analyzing potential malignancy risk factors in mitoxantrone-treated patients. Hazard ratios, $95 \%$ confidence intervals, and $p$ values are depicted. The reported hazard ratio for age at treatment initiation refers to 5-year intervals and that for cumulative mitoxantrone dose to a comparison of patients having received $>75$ vs $\leq 75 \mathrm{mg} / \mathrm{m}^{2}$. For definition of "other immunosuppressant," see the Methods section. Note that only higher age at treatment initiation shows a significant elevation above the dashed line while other factors including higher cumulative dose do not seem to increase the risk.

German patients with MS not having received mitoxantrone were available for our study. Treatment of about one-third of our patients with other immunosuppressive drugs might have led us to overestimate the mitoxantrone-related risk. This may only weakly apply to colorectal cancer, as only one of 7 patients had received other immunosuppressive drugs.

Despite an increased risk of AML and colorectal cancer, the overall incidence of all malignancies in our cohort appears acceptably low to justify mitoxantrone treatment in severely affected patients with MS if no better therapeutic alternative is available. Mitoxantrone is currently the only approved treatment for patients with secondary progressive MS without superimposed relapses and should be considered in patients with rapidly evolving disabling disease; moreover, many of the new and highly effective immunotherapies are not available to the majority of patients in a number of countries for economic reasons and therefore mitoxantrone is still being used for patients with very active relapsing forms of the disease. ${ }^{3}$ In practical terms, posttreatment colonoscopy might improve the risk-benefit ratio of this highly active immunosuppressive drug.

\section{AUTHOR CONTRIBUTIONS}

Dr. Buttmann: conceived and designed the study, supervised chart reviews, collected follow-up data, analyzed data, drafted and edited the manuscript, had access to all data, and takes full responsibility for the data, accuracy of the data analysis, and the conduct of the research. Ms. Seuffert: performed manual chart review, analyzed data. Dr. Mäder: performed statistical analyses, edited the manuscript. Dr. Toyka: assessed data, edited the manuscript for intellectual content.

\section{ACKNOWLEDGMENT}

The authors are deeply grateful to the patients and their relatives and physicians for supporting this study.

\section{STUDY FUNDING}

Supported by university research funds; no pharmaceutical industry sponsoring.

\section{DISCLOSURE}

M. Buttmann served as a consultant for Teva Pharma and Roche, received grants for clinical research from Merck Serono and Novartis related to molecular biomarkers of multiple sclerosis, received speaker fees from Biogen, and received congress travel grants from Bayer HealthCare Pharmaceuticals, Genzyme, and Novartis. L. Seuffert and U. Mäder report no disclosures relevant to the manuscript. K. Toyka received a research grant from Merck Serono related to neuromyelitis optica and unrestricted research funds from the University Medical School as Senior Research Professor. Go to Neurology.org for full disclosures.

Received December 2, 2015. Accepted in final form March 2, 2016.

\section{REFERENCES}

1. Martinelli Boneschi F, Vacchi L, Rovaris M, Capra R, Comi G. Mitoxantrone for multiple sclerosis. Cochrane Database Syst Rev 2013;5:CD002127.

2. English C, Aloi JJ. New FDA-approved disease-modifying therapies for multiple sclerosis. Clin Ther 2015; 37:691-715.

3. Carra A, Macias-Islas MA, Gabbai AA, et al. Optimizing outcomes in multiple sclerosis: consensus guidelines for the diagnosis and treatment of multiple sclerosis in Latin America. Ther Adv Neurol Disord 2011;4: 349-360.

4. Marriott JJ, Miyasaki JM, Gronseth G, O’Connor PW; Therapeutics and Technology Assessment Subcommittee of the American Academy of Neurology. Evidence report: the efficacy and safety of mitoxantrone (Novantrone) in the treatment of multiple sclerosis: report of 
the Therapeutics and Technology Assessment Subcommittee of the American Academy of Neurology. Neurology 2010;74:1463-1470.

5. Martinelli V, Cocco E, Capra R, et al. Acute myeloid leukemia in Italian patients with multiple sclerosis treated with mitoxantrone. Neurology 2011;77:1887-1895.

6. Stroet A, Hemmelmann C, Starck M, et al. Incidence of therapy-related acute leukaemia in mitoxantrone-treated multiple sclerosis patients in Germany. Ther Adv Neurol Disord 2012;5:75-79.

7. Lebrun C, Debouverie M, Vermersch P, et al. Cancer risk and impact of disease-modifying treatments in patients with multiple sclerosis. Mult Scler 2008;14:399-405.
8. Le Page E, Leray E, Edan G; French Mitoxantrone Safety Group. Long-term safety profile of mitoxantrone in a French cohort of 802 multiple sclerosis patients: a 5-year prospective study. Mult Scler 2011;17:867-875.

9. Lebrun C, Vermersch P, Brassat D, et al. Cancer and multiple sclerosis in the era of disease-modifying treatments. J Neurol 2011;258:1304-1311.

10. Roncucci L, Mariani F. Prevention of colorectal cancer: how many tools do we have in our basket? Eur J Int Med 2015;26:752-756.

11. Marrie RA, Reider N, Cohen J, et al. A systematic review of the incidence and prevalence of cancer in multiple sclerosis. Mult Scler 2015;21:294-304.

\section{Neurology ${ }^{\circledR}$ Online CME Program}

Earn CME while reading Neurology. This program is available only to online Neurology subscribers. Simply read the articles marked CME, go to Neurology.org, and click on CME. This will provide all of the information necessary to get started. The American Academy of Neurology (AAN) is accredited by the Accreditation Council for Continuing Medical Education (ACCME) to sponsor continuing medical education for physicians. Neurology is planned and produced in accordance with the ACCME Essentials. For more information, contact AAN Member Services at 800-879-1960.

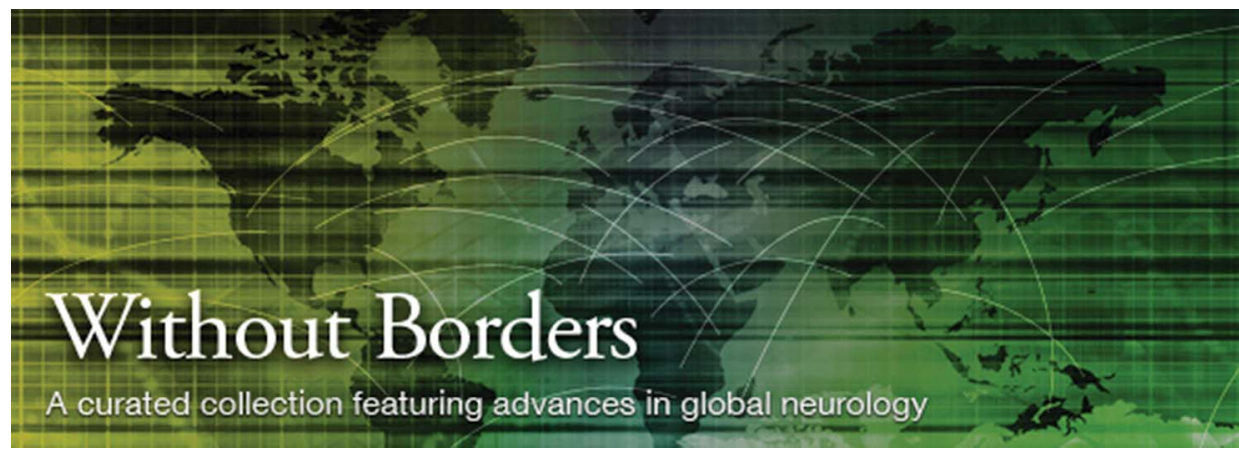

\section{NEW!}

\section{Without Borders - A curated collection featuring advances in global neurology}

This Neurology ${ }^{\circledR}$ special interest Web site is the go-to source for tracking science and politics of neurology beyond the United States, featuring up-to-the-minute blogs, scholarly perspectives, and academic review of developments and research from Neurology journals and other sources. Curated by Gretchen L. Birbeck, MD, MPH.

Expand your world view at Neurology.org/woborders. 


\section{Neurology}

\section{Malignancies after mitoxantrone for multiple sclerosis: A retrospective cohort study}

Mathias Buttmann, Linda Seuffert, Uwe Mäder, et al.

Neurology 2016;86;2203-2207 Published Online before print May 11, 2016

DOI 10.1212/WNL.0000000000002745

\section{This information is current as of May 11, 2016}

Updated Information \& Services

References

Subspecialty Collections

Permissions \& Licensing

Reprints including high resolution figures, can be found at: http://n.neurology.org/content/86/23/2203.full

This article cites 11 articles, 2 of which you can access for free at: http://n.neurology.org/content/86/23/2203.full\#ref-list-1

This article, along with others on similar topics, appears in the following collection(s):

Cohort studies

http://n.neurology.org/cgi/collection/cohort_studies

Multiple sclerosis

http://n.neurology.org/cgi/collection/multiple_sclerosis

Information about reproducing this article in parts (figures,tables) or in its entirety can be found online at:

http://www.neurology.org/about/about_the_journal\#permissions

Information about ordering reprints can be found online:

http://n.neurology.org/subscribers/advertise

Neurology ${ }^{\circledR}$ is the official journal of the American Academy of Neurology. Published continuously since 1951, it is now a weekly with 48 issues per year. Copyright @ 2016 American Academy of Neurology. All rights reserved. Print ISSN: 0028-3878. Online ISSN: 1526-632X.

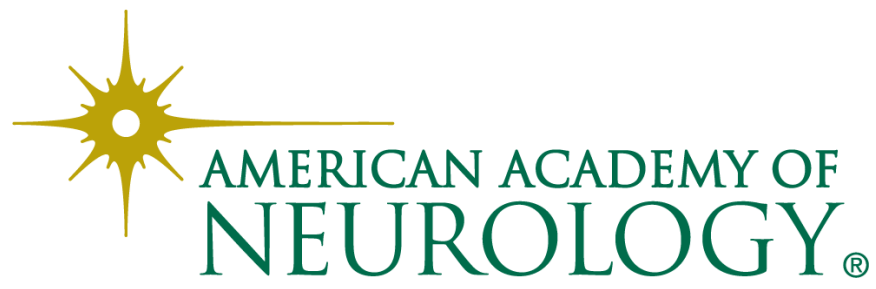

